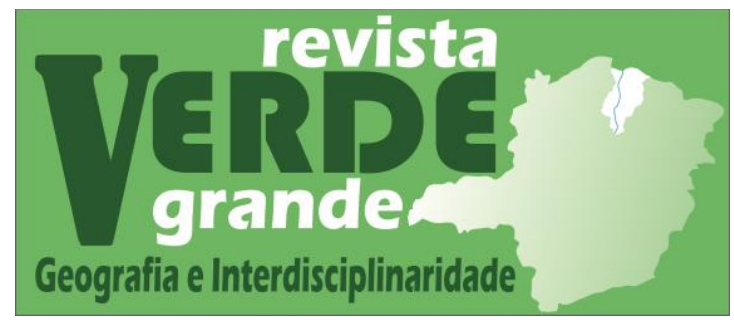

Volume 01, no. 02, 2019

https://www.periodicos.unimontes.br/index.php/verdegrande

\title{
O ESTUDO DO MEIO "PAISAGENS E LUGARES DO CENTRO HISTÓRICO DE NATAL - RN
}

Pablo Sebastian Moreira Fernandez ${ }^{1}$ https://orcid.org/0000-0002-5594-6990

\footnotetext{
${ }^{1}$ Doutor em Geografia - UFG. Professor do Centro de Educação - Departamento de Práticas Educacionais e Currículo Universidade Federal do Rio Grande do Norte. E-mail: pablosmfernandez@gmail.com
}

\section{Resumo}

Este relato de experiência traz como objeto de leitura e análise a prática de estudos do meio como possibilidade ao Ensino de Geografia. Esta prática muito comum na Geografia como caminho metodológico de processos de pesquisa, torna-se também um potente caminho pedagógico e experiencial. A escolha pare esta ação dependerá do contexto onde se insere este professor (ou pesquisador), porém em nossas atividades docentes no curso de Pedagogia da UFRN, temos construído e aprimorado um trajeto didático no centro histórico da cidade do Natal - RN. O estudo do meio, ainda indica uma reflexão sobre a linguagem na qual os sujeitos apresentam suas experiências caminhantes de modo livre e pessoal, indicando possibilidades de escritas que transcendem um relato padronizado e homogêneo, mas vivo, criativo, inspirado na escrita etnográfica.

Palavras-chave: Estudo do Meio, Centro Histórico de Natal, Ensino de Geografia.

As cidades são ruas, avenidas de troca e comércio, o aglomeramento físico de pessoas, uma multidão caminhando nas calçadas movidas por curiosidade, surpresa, pela possibilidade do encontro, a vida humana não acima da confusão mas no meio dela. A vitalidade das cidades depende do caminhar. James Hillman (1993).

Este relato apresenta um conjunto de práticas educativas que tenho realizado em cursos de Pedagogia na disciplina Ensino de Geografia, e tem como intenção ampliar as leituras e debates teóricos realizados em sala de aula, neste texto especificamente tratará de turmas de estudantes da Universidade Federal do Rio Grande do Norte, do campus Natal. Esta disciplina parte de um entendimento que os saberes geográficos participam de inúmeros e múltiplos processos de ensino e aprendizagem, e de que a Geografia é além de uma disciplina escolar ou ciência, um conhecimento fundado no corpo e nas corporeidades, na cultura e na linguagem, além de fundar um pensamento crítico e criativo para "nossas" leituras sobre a Terra. 
O Estudo do Meio "paisagens e lugares do centro histórico de Natal -RN

Pablo Sebastian Moreira Fernandez

Esta disciplina que tenho trabalhado em 3 módulos, de modo geral se constituiria do seguinte modo: 1) História e Epistemologia da Geografia; 2) Conceitos "fundantes" e categorias escolares, articulado à linguagens como cartografia, música, desenho, e outras; e 3) planejamento de um Estudo do Meio, a partir de um lugar pré-determinado. Nossa escolha tem se dado para a cidade desde uma pesquisa realizada sobre o caminhar como possibilidade de formação de um olhar paisagístico e de expressão de experiências (FERNANDEZ, 2008), considerando-a como um rico espaço de análise geográfica que adensa elementos materiais (os fixos, as construções, a cidade "palimpsesto" com suas camadas de tempo) e imateriais, como a memória, a história de seus moradores, o pertencimento, os riscos e incertezas, o cotidiano, os trajetos cotidianos.

O recorte de nosso estudo do meio é o Centro da cidade do Natal (capital do RN) justificado na possibilidade de caminhar (em grupo e em um período) e vivenciar lugares diversos e culturalmente significativos: igrejas e arquitetura histórica, espaços de convivência, de trabalho, de circulação e trânsito (terminais e paradas), museus e espaços de arte, lugares revitalizados, espaços oficiais e monumentos do poder, o rio Potengi. Desta escolha, o ponto de partida de nosso caminhar pela cidade é uma praça próxima a terminais de transporte permitindo o "encontro" da turma, momento de conversa que irá despertar duas impressões gerais: um de total desconhecimento (e assim de surpresas), outro de espaço significativo e emblemático (revivido nas memórias de outros tempos), criando uma primeira cartografia afetiva, iniciada em uma atividade de localização e orientação utilizando um mapa da cidade.

Figuras 1 e 2: Início do Estudo do Meio e Atividade de orientação com mapa e bússola.
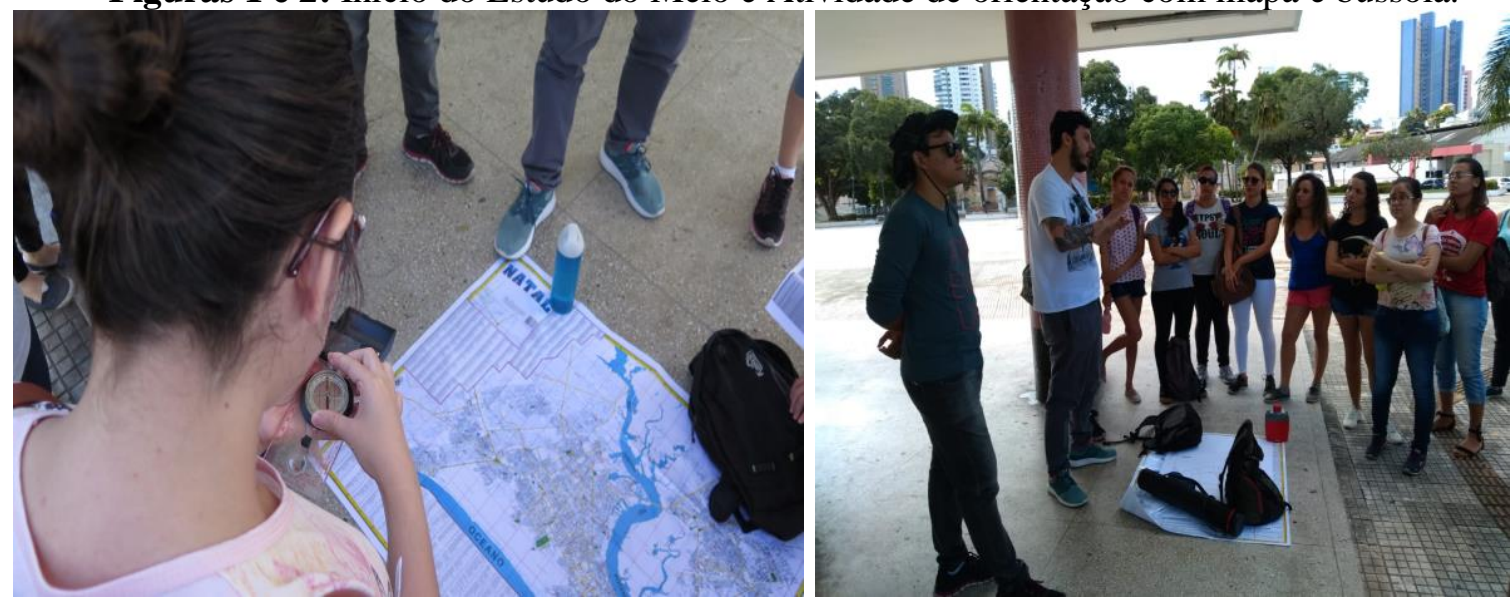

Fonte: Pablo S. M. Fernandez (2019)

A partir deste entendimento que o caminhar pela cidade pode ser um potente "recurso" para o despertar do olhar geográfico de um sujeito e de uma sociedade, partiu-se de um Roteiro de Observação (no formato de um folder) com questões que poderiam orientar o olhar 
O Estudo do Meio "paisagens e lugares do centro histórico de Natal -RN

Pablo Sebastian Moreira Fernandez

destes estudantes buscando um sentido de leitura geopoética do mundo e de experiência geográfica. Dentre estas: É possível estabelecer sua localização em diferentes escalas (do lugar ao municipal, regional, nacional, global)? Onde este lugar está situado na cidade do Natal, em qual região? Sul, Norte? Qual a distância deste lugar com a Universidade aonde estudam ou com outros lugares cotidianos (trabalho, casa de familiares, amigos,...)? Pode-se considerá-lo longe ou perto a partir da escala vivida? Estas questões irão fomentar a busca de cada caminhante.

Oficialmente, o recorte que delimitamos como Centro Histórico (próxima a foz do rio Potengi e do Ocenao Atlântico) abarcaria os bairros da Ribeira (parte baixa, uma planície alagável) e a Cidade Alta, delimiração do espaço que será percebida na transposição do espaço físico, sentido corporalmente através do caminhar com maior esforço por uma ladeira. Neste trecho do percurso, localiza-se um mirante de onde pode-se avistar esta "quebra" do relevo, permitindo compreender uma geomorfologia deste sítio urbano. Neste ponto, foi utilizado um mapa do estado do Rio Grande do Norte, destacando em nossa leitura o rio Potengi, em busca de sua nascente, das regiões e lugares por onde passa até desembocar "ali" diante de nossos olhos.

Figura 3: Paisagem da "cidade baixa", foz do rio Potengi e ponte Newton Navarro.

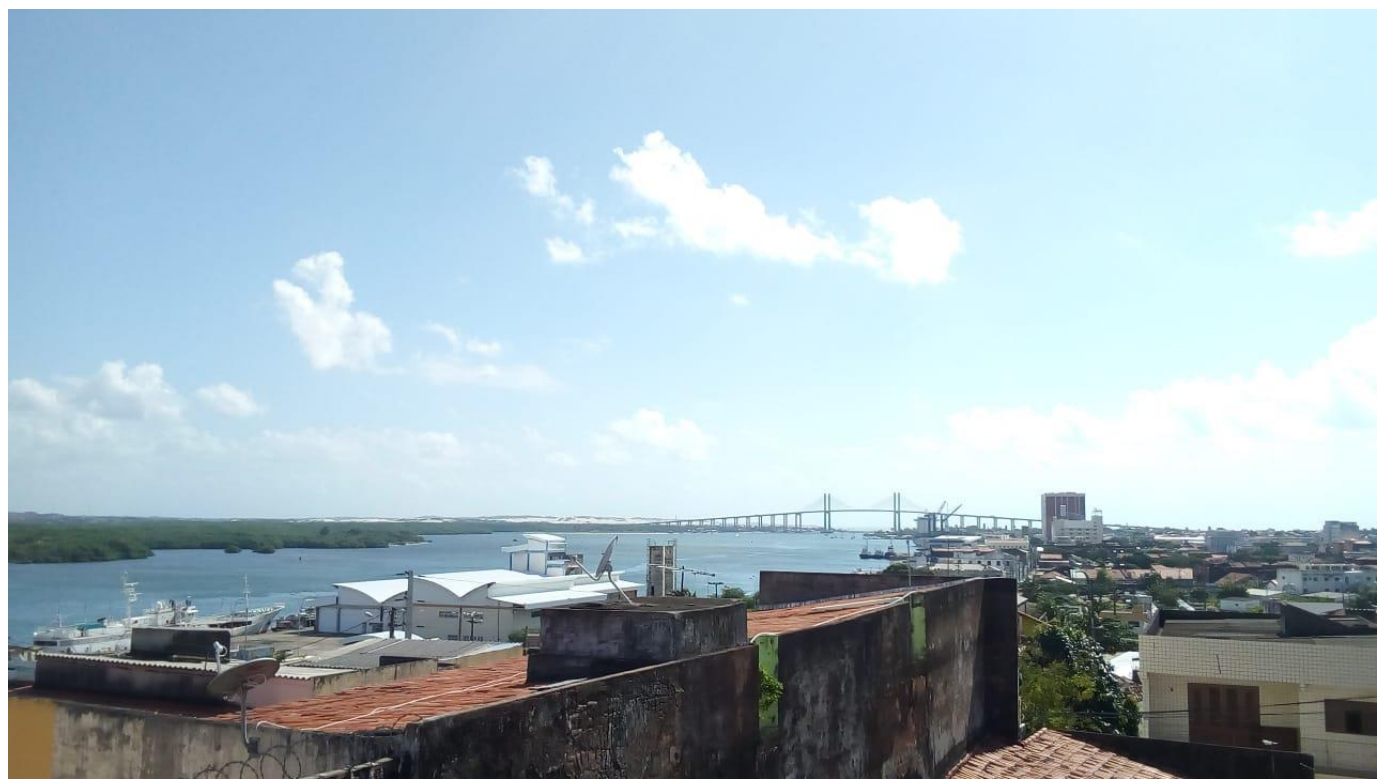

Fonte: Pablo S. M. Fernandez (2019)

Dando continuidade ao estudo do meio e de nosso caminhar pela cidade, o grupo percorreu uma área que abriga igrejas, praças, calçamentos de pedra, prédios públicos e o "marco zero" da cidade. Neste ponto que tem uma rosa dos ventos impressa em seu 


\section{O Estudo do Meio "paisagens e lugares do centro histórico de Natal -RN}

Pablo Sebastian Moreira Fernandez

calçamento, fizemos uma primeira rodada de conversas acerca das impressões e assim delimitamos temas de pesquisa pela lente geográfica. Sendo estes: O Sítio Urbano, o "chão" lugar onde a cidade se formou e, desse modo, influenciou seu desenvolvimento e cultura, especialmente quanto ao seu aspecto natural (a planície e o mangue, e a expansão para outras áreas) que pode favorecer ou atrapalhar seu desenvolvimento; A toponímia expressa no conhecimento dos nomes de cada lugar, visto que é um dado que possui valor histórico, político e poético, e, permite conhecer a dinâmica e os processos de um lugar e a relação com o ambiente; $\mathrm{O}$ trabalho que molda e transforma o espaço e as paisagens, sendo o mediador da técnica e da tecnologia na relação Sociedade x Natureza; as paisagens que são como impressões da cultura no espaço da cidade, podendo ser revelada em pixações, grafites, prédios, na própria corporeidade; Os lugares de encontro, lazer, descanso e como estes nos revelam pertencimento e topofilia.

Figuras 4 e 5: Beco da Lama, área de revitalização pelo poder público e grafites.
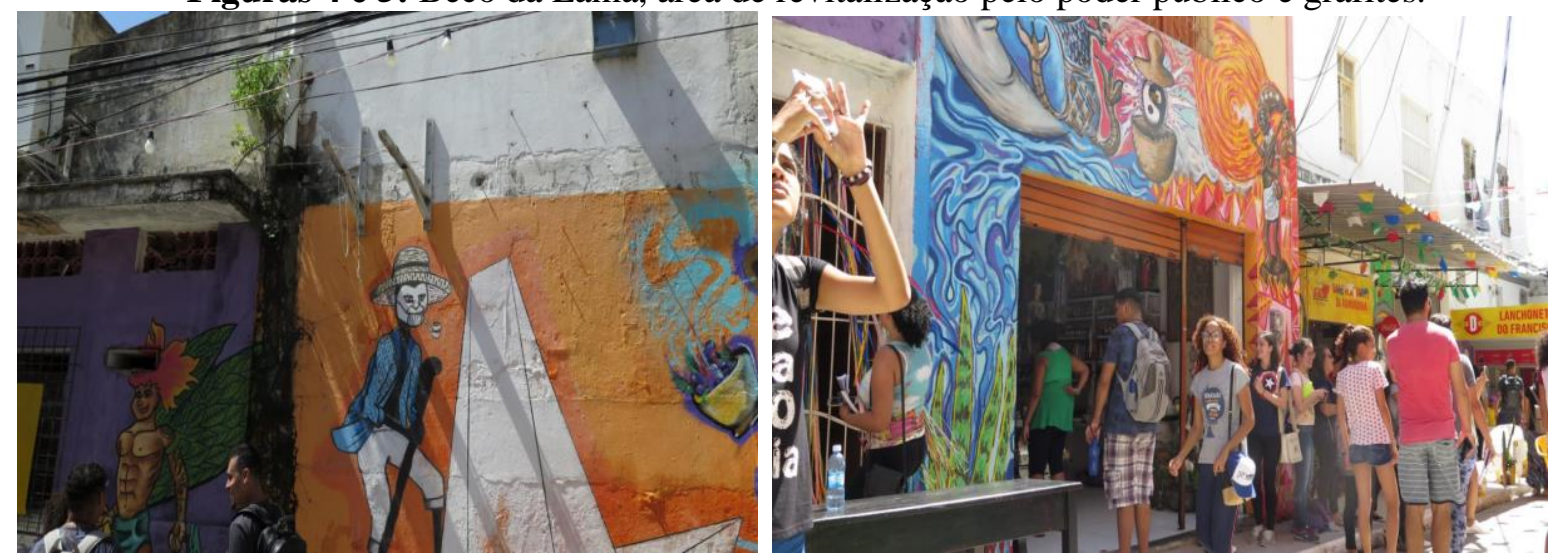

Fonte: Pablo S. M. Fernandez (2019)

\section{Narrando as experiências do percurso}

Um relatório deve expressar as experiências que emergem no Estudo do Meio, e por isso a escrita tem "tom" de narrativa, sendo em primeira pessoa e indicando as possibilidades (novos olhares) de uma atividade como esta na formação de professores (e de alunos). Com o fim do percurso, é realizada uma roda de conversa aonde cada um dos participantes é convidado a relatar e a expressar suas impressões e paisagens vividas. A linguagem narrativa inicialmente tem um formato livre, podendo ser uma crônica, um conjunto de poesias, o diário de campo e sua sistematização próxima das estruturas documental da Etnografia (MAGNANI, 2009) com esboços, ideias soltas, um ensaio fotográfico ou de vídeo, o que criam ampliações diante das formas tradicionais de relato. 


\section{O Estudo do Meio "paisagens e lugares do centro histórico de Natal -RN}

Pablo Sebastian Moreira Fernandez

Figura 6: Paisagens avistadas no Estudo do Meio: Igrejas, calçamento de pedras, rio Potengi, Casa de Câmara Cascudo e arquitetura histórica.

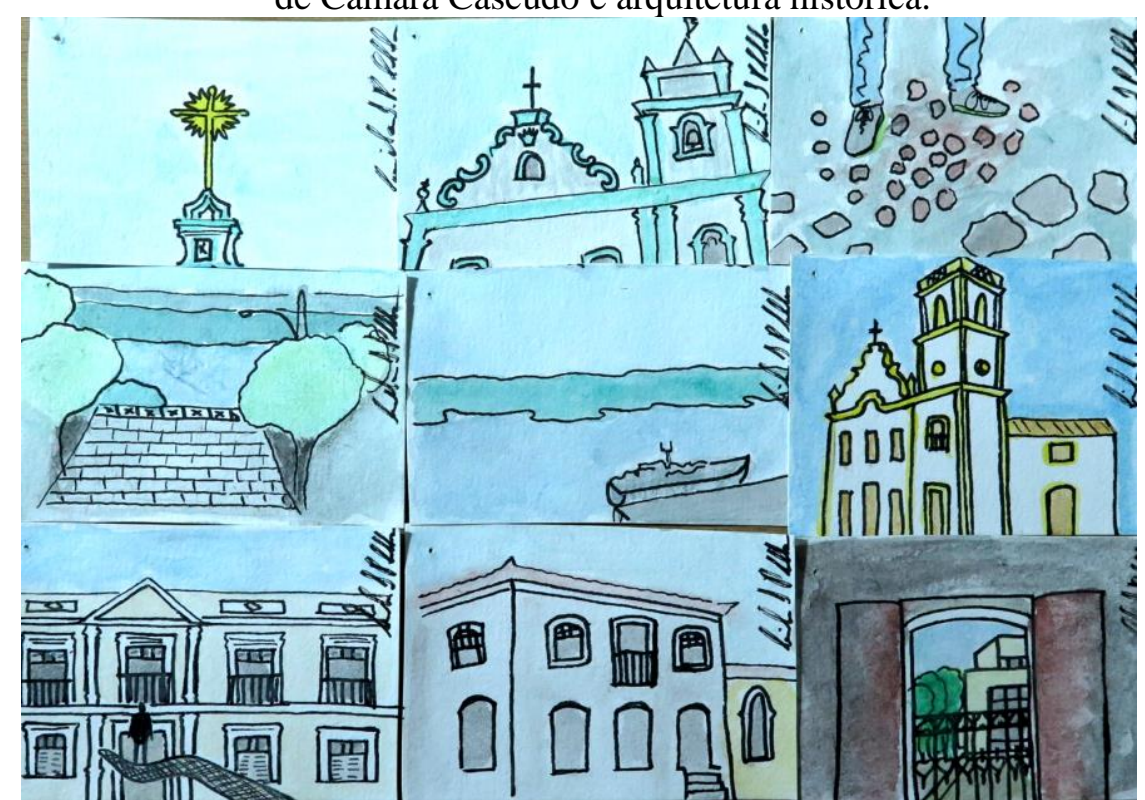

Fonte: Acervo do autor a partir de um diário de campo (2018).

A partir de uma leitura destes relatos, vê-se um duplo movimento de produção de conhecimentos espaciais: 1) o caminhar pela cidade e o reconhecimento do sujeito como agente produtor do espaço e 2) sua narrativa, ou expressão do que foi vivido sendo entendida como uma geo-grafia, tanto como expressão significativa como linguagens a serem incorporadas às suas práticas pedagógicas. $\mathrm{O}$ que se nota sobre o Estudo do Meio é que este "instrumento" permite uma aproximação conceitual, teórica e prática entre professores e alunos, na tentativa de compreensão de singularidades, identidades, espaços e tempos que se apresentam na sala de aula, na escola e fora dela: no mundo. Um exemplo deste exercício de olhar foi quando uma aluna empunhando uma fotografia "antiga" da praça (ponto de partida) sai caminhando em busca do mesmo ângulo em que uma ponte foi enquadrada, pois queria compreender o ponto de vista daquele fotógrafo.

\section{REFERÊNCIAS}

HILLMAN, James. Cidade \& Alma. São Paulo: Studio Nobel, 1993.

MAGNANI, José Guilherme Cantor. A rua Quinze, de praça a praça: um exercício antropológico. NAU - Núcleo de Antropologia Urbana da USP. São Paulo, 2009.

FERNANDEZ, Pablo S. M. Narrativas Urbanas de um Caminhante. Dissertação de mestrado apresentado ao Programa de Pós-Graduação em Educação da Universidade Estadual de Campinas/Faculdade de Educação. FAPESP, 2008. 